\title{
Congenital Malformations: Prenatal Diagnosis and Management
}

\section{Ahmed Abdalla Bashir ${ }^{1,2}$}

${ }^{1}$ Al Mana General Hospital, Department of Pediatrics Jubail, Kingdom of Saudi Arabia

${ }^{2}$ Prof. Stanley Nelson Lab., David Geffen Medical School, Department of Genetics, University of California, CA, USA

Congenital malformations are estimated to be $2-4 \%$ of all births. Despite their relatively low prevalence, fetal malformations are responsible for approximately $30 \%$ of perinatal deaths, and considerable infant morbidity in developed countries [1]. Fetal malformlformations can be defined as structural or functional anomalies that occur during intrauterine life and can be identified prenatally, at birth or later in life.

Congenital anomalies are also known as birth defects, congenital disorders or congenital malformations. Conginital disorders are the major cause of new born deaths within the perinatal peroid ,which can result in long-term disability with a significant impact on individuals, families, societies and health-care systems [2]. Prenatal diagnosis of congenital disease provides information for decisions during pregnancy and appropriate treatment prentally (timed delivery in tertiary care centers), it is assumed to improve perinatal and long term outcome. However, this assumption has been demonstrated only for few specific subsets of malformations, and with conflicting results. Bonnet et al. [3] showed that prenatal diagnosis reduced the overall pre- and post-operative mortality in fetuses affected by complete transposition. In another study [4] preoperative conditions were improved in cases with complete transposition and hypoplastic left heart, without improvement in perinatal mortality. At 2 years the survival was the same in diagnosed as in undiagnosed fetuses with pulmonary Artesia with intact ventricular septum [5]. No improvement was seen in cases of hypoplastic left heart diagnosed antenatally versus postnatally [6]. Prenatal diagnosis, (discovered Over the last two decades), has greatly benefited from advances in ultrasound technology and in our ability to detect microscopic and submicroscopic chromosome abnormalities as well as single gene disorders, leading to substantive improvements in detection of such congenital anomalies. At present, invasive prenatal diagnosis continues to be the gold standard for pregnancies at increased risk for chromosomal anomaly or other genetic disease, with chorionic villus sampling being the procedure of choice for the first trimester. Whereas mid-trimester amniocentesis continues to be the most common form of invasive procedure for prenatal diagnosis [7]. Still, invasive techniques are restricted to subgroups at risk for anomalies; such time-consuming procedures are believed to be cost-effective, also accounting for procedure-related abortive risks. In the lowrisk population prenatal diagnosis generally consists of screening procedures by means of ultrasound and maternal serum biochemistry. A major impact of antenatal diagnosis of malformations is related to the severity of the malformations detected. Most severe defects are reportedly detected earlier than minor ones, which is especially relevant in many countries where only before viability is termination of pregnancy authorized by law [8].

The potential of ultrasound for detecting structural malformations were derived from populations at specific risk investigated, the data showed that the sensitivities are as high as $85-90 \%$.Those data could not be replicated in the general population. The detection rates data using ultrasound for screening for fetal malformations do vary widely, showing a range from $8.7 \%$ to $85 \%$ [9]. Such wide differences reflect varying criteria for definition of malformation, postnatal examination,

\section{Publication History:}

Received: December 31, 2018

Accepted: March 06, 2019

Published: March 08, 2019

\section{Keywords:}

Congenital, Hypopituitarism, Partial, Complete, Association, Magnetic resonance imaging (MRI), Saudi Arabia

selection of study population, prevalence of specific anomalies within a population, and other methodology issues (e.g., single hospital versus multicenter setting, expertise and skills of operators, use of standardized protocols for ultrasonographic examination [10]. Ultrasound imaging is now routinely used in most European and North American countries for the purpose of screening pregnancies for fetal malformations. The modalities, reliability and value of such screeningin each country, however, are controversial. . .

Specific anomalies, such as agenesis of corpus callosum, posterior fossa cysts, cerebral cleft, and migrational disorders such as lissencephaly, could be investigated by Magnetic resonance imaging [11]. Use of Magnetic Resonance Imaging is nonetheless uncommon in clinical practice, being restricted to specific indications [12]. It should be first noted that most structural anomalies are increasingly detected with advancing gestation [8]. In early pregnancy, it is possible to recognize with confidence certain types of fetal malformations, like anencephaly, which can be reliably diagnosed at 10-14 weeks of pregnancy [13]. In some cases omphalocele and limb anomalies are also definable using ultrasound in the first trimester, while other structural anomalies, like urinary tract abnormalities, are detectable later in pregnancy [14]. Screening for neural tube defects may ideally involve ultrasound examination in conjunction with maternal serum alpha-fetoprotein screen [12]. On comparison of the two methods, maternal serum screening was found to have a slightly greater sensitivity compared to ultrasound [15].

Ultrasound screening for fetal structural abnormalities is generally recommended at 19-21 weeks of gestational age. The accuracy in detecting malformations by ultrasound, however, shows great variability among centres and operators. Nonetheless, the overall sensitivity for ultrasonographically detectable fetal malformations was $35 \%$ in tertiary facilities significantly higher compared to $13 \%$ in community hospitals, suggesting that operator experience, skills, and training are important determinant [10]. Other factors affecting

"Corresponding Author: Dr. Ahmed Abdalla Bashir, Al Mana Genera Hospital, Department of Pediatrics Jubail, Kingdom of Saudi Arabia; E-mail: abashir@tulane.edu

Citation: Bashir AA (2019) Congenital Malformations: Prenatal Diagnosis and Management. Int J Pediatr Neonat Care 5: 149. doi: https://doi.org/10.15344/24552364/2019/149

Copyright: (C) 2019 Bashir. This is an open-access article distributed under the terms of the Creative Commons Attribution License, which permits unrestricted use, distribution, and reproduction in any medium, provided the original author and source are credited. 
sensitivity are: single vs multicentre study, type of malformation (major vs minor, single vs multiple, natural history of the disease during fetal life), gestational age at ultrasound examination, length and accuracy of follow-up (some malformations are detected in early or even late infancy) [16].

Ultrasound screening at 10-14 weeks has included measurement of nuchal translucency, (which is the maximum thickness of the subcutaneous translucency between the skin and the soft tissue overlying the cervical spine of the fetus) [17]. An increased nuchal translucency is associated with aneuploidy and cardiac malformations [18].

Combined with ultrasound results or alone, maternal serum biochemistry is a valid tool used for screening for chromosomal anomalies toward the end of the first trimester or in the early midtrimester [19]. Use of second trimester ultrasound for detection of chromosomal anomalies was first suggested in 1985 [20]. Chromosomal defects were progressively found to be associated with certain sonographic features, including biometric parameters (e.g., short length of femur and humerus, pyelectasis, large nuchal fold, ventriculomegaly, early fetal growth restriction) and morphologic signs (e.g., choroids plexus cysts, echogenic bowel, echogenic intracardiac focus). Their reliability is undoubtedly increased in pregnant women at increased risk for Down syndrome, but the positive predictive value for each marker is dramatically decreased in low-risk women when applying the Bayes' theorem [21]. "Down syndrome markers" make up a heterogeneous group, including common findings in normal fetuses, like the echogenic intracardiac focus which occurs in approximately $5 \%$ of fetuses. As a result, ultrasound soft markers lead to a small increase in detection of congenital anomalies but a large increase in false positives. The detection of any of the above markers during a routine sonogram warrants careful scanning aimed at identifying additional markers because the finding of multiple markers indicates high risk for chromosomal anomaly [22]. Computerised programmes have been developed which permit to estimate the adjusted risk for aneuploidy by combining background risk (based on maternal age) and biochemical screening together with the above ultrasound features [23]. These are useful when a marker is a chance finding during routine ultrasound scanning., At present, in the absence of studies validating second trimester sonography for the purpose of screening the general population for chromosomal anomalies, such use of ultrasound is not a recommended procedure [24]. For example, it has been shown that the inclusion of soft markers when screening at 20 - 22 weeks improves the detection rate of malformations from $50 \%$ to $54 \%$; however, it also increases the number of false positive results from $0.04 \%$ to $0.53 \%$ [25]. Boyd PA, et al. studied two terminations of pregnancies carrying unaffected fetuses were performed. Moreover, the finding of a marker may adversely affect the pregnancy due to anxiety caused to the mother [26].

Structural congenital heart disease (CHD) described in postnatal life has been detected in utero by fetal cardiac ultrasound [16]. From published series of structural cardiac anomalies detected during fetal life it is apparent that the closest figure to the true incidence of CHD in the general population of fetuses is 1 percent [27]. Prenatal and postnatal series discrepancies can be partly explained by the unexpectedly high tendency towards spontaneous intrauterine demise and early postnatal death of fetuses with cardiac abnormalities [28]. It is clear that there is a strong association between the presence of fetal cardiac disease, extracardiac abnormalities and aneuplodies [29]. While the incidence of chromosomal abnormalities in fetuses with CHD ranges from 17 to 48 percent [29-32] only 5-10 per cent of infants with congenital heart disease are found to be chromosomically abnormal [33]. Associated extracardiac structural malformations are more frequent as well, i.e. 19\% prenatally compared to $13 \%$ at birth in the largest Italian series [28]. This discrepancy is likely to be due to the tendency toward spontaneous fetal loss of pregnancies carrying chromosomically and/or structurally abnormal fetuses; however it is difficult to prove it, because of the high pregnancy termination rate altering the natural history of disease. The recent reports by Paladini D, Rustico and others on 67 cases of anomalies of ventricular diagnosed prenatally: chromosomal aberrations and extracardiac malformations were found in $18 \%$ and $37 \%$, respectively [34]. There were $48 \%$ livebirths in isolated cases and $15 \%$ in cases with extracardiac anomalies. The frequency of association with aneuploidies and/or extracardiac anomalies is different for differing congenital heart diseases, being highest for atrio-ventricular septal defects $(48 \%)$ and lowest for complete transposition of the great arteries (concordant atrioventricular connections with discordant ventriculoarterial connections) (0-2.6\%) [28,29].

Ultrasound screening for fetal cardiac malformations is part of routine ultrasound screening at 19-21 weeks, according to scanning protocols including the four-chamber view [27]. In the setting of a low-risk population, a four-chamber view of the fetal heart potentially allows, at the best of its performance, the detection of only $40 \%$ of fetuses with complex heart disease [35]. Most missed cardiac lesions commonly involve outflow tract anomalies such as complete transposition, common arterial trunk, and aortic coarctation or minor anomalies such as atrial septal defects (septum secundum), small ventricles. The same considerations reported above for screening of congenital defects hold true for cardiac malformations, namely, different sensitivities for different settings and malformations $[2,27,36]$. Atrial septal defects, mild pulmonary or aortic stenosis $[10,16,27]$. Incorporating visualization of the outflow tracts and the great arteries into the scanning protocol would increase the detection rate to $65-70 \%$. However, data on this type of screening is still limited $[37,38]$. Fetal echocardiography should be performed in groups selected on the basis of patient history and sonographic anomalies or markers, including extracardiac anomalies, maternal diabetes, infection, suspicious scan on screening, chromosomal aberrations. In this context, also should be listed abnormal biochemical screening or maternal age older than 34 years coupled with refusal of invasive karyotyping, increased nuchal translucency, early onset (below 32 weeks) fetal growth restriction, fetal arrhythmias, family history of congenital heart disease, hydrops, exposure to teratogenic agents $[16,39]$. Estimates of diagnostic accuracy of fetal echocardiography depend on the prevalence of those anomalies which are most difficult to detect, like mild pulmonary stenosis, small septal defects, and aortic coarctation [40].

In the coming Future directions require the assessment of costeffectiveness of screening ultrasound in differing settings in terms of populations and health care provision systems. A large, multicentre study of minor markers of Down syndrome is needed on low-risk patients to replace the data extrapolated from high-risk patient to the low-risk population [21,26]. Apart from methodological issues, our knowledge of certain conditions is to be improved. For example, screening ultrasonography has been shown to increase the frequency of prenatally diagnosed hydronephrosis. Many infants with congenital hydronephrosis remain without symptoms for months or even years before diagnosis, it should be important to establish whether prenatal diagnosis would benefit otherwise asymptomatic infants by preserving 
their renal function. The poorly understood and currently under investigation is the in utero development of some types of congenital heart defects.41Further assessment is needed for the incorporation of visualization of outflow tracts into the ultrasound screening protocol for congenital heart disease [42]. Because ultrasound can detect associations of specific anomalies, detection of patterns of anomalies may help make a diagnosis or determine which pregnant women should be offered invasive testing. The specificity of associations of the most frequent patterns has been analysed, and different patterns were found to aggregate in a relatively small number of clusters, so that several patterns can be considered in non-random associations [43]. Proper analysis of antenatal sonographic data sets might enable detection of new patterns of associations of anomalies, enhancing further the diagnostic potential of the test. It is difficult to establish to what extent information provided by Magnetic Resonance Imaging may warrant changes in patient counselling and management, so that further studies are needed to assess how additional information from MRI may affect outcome [44]. In the meantime, real-time fast acquisition MRI methods are being developed.

\section{Competing Interests}

The author declare that there is no competing interests regarding the publication of this article.

\section{Reference}

1. Steele MW, Breg WR (1966) Chromosome analysis of human amniotic fluid cells. Lancet 1: 383-385.

2. Chitayat $D$, Babul-Hirji $R$ (2000) Genetic counselling in prenatally diagnosed non-chromosomal fetal abnormalities. Curr Opin Obstet Gynecol 12: 77-80.

3. Jenkins TM, Wapner RJ (1999) First trimester prenatal diagnosis: chorionic villus sampling. Semin Perinatol 23: 403-413.

4. Douglas Wilson R (2000) Amniocentesis and chorionic villus sampling. Cur Opin Obstet Gynecol 12: 81-86.

5. Fetal Abnormalities (1997) Guidelines for Screeening, Diagnosis and Management. London, UK: RCPCH, RCOG. Royal College of Obstetricians and Gynaecologists, Royal College of Paediatrics and Child Health. Background evidence supporting the guidelines.

6. Luck CA (1992) Value of routine ultrasound scanning at 19 weeks: a four year study of 8849 deliveries. Br Med J 304: 1474-1478.

7. Romero R (1993) Routine obstetric ultrasound. Ultrasound Obstet Gynecol 3: $303-307$

8. Crane JP, LeFevre ML, Winborn RC, Evans JK, Ewingman BG, et al. (1994) A randomised trial of prenatal ultrasonographic screening: Impact on the detection, management, and outcome of anomalous fetuses. Am J Obstet Gynecol 171: 392-399.

9. Levine D, Barnes PD, Madsen JR, Abbot J, Tejas Meta T, et al. (1999) Central nervous system abnormalities assessed with magnetic resonance. Obstet Gynecol 94: 1011-1019.

10. Pilu G, Perolo A, Falco P, Visentin A, Gabrielli G, et al. (2000) Ultrasound of the central nervous system. Curr Opin Obstet Gynecol 12: 93-103.

11. Grandjean $H$, Larroque D, Levi S (1999) The performance of routine ultrasonographic screening of pregnancies in the Eurofetus Study. Am J Obstet Gynecol 181: 446-454.

12. Johnson P, Sebire NJ, Snijders RJM, Tunkel S, Nicolaides KH, et al. (1997) Ultrasound screening for anencephaly at 10-14 weeks of gestation. Ultrasound Obstet Gynecol 9: 14-16.

13. Chitty LS, Pandya PP (1997) Ultrasound screening for fetal abnormalities in the first trimester. Prenat Diagn 17: 1269-1281.

14. Sebire NJ, Noble PL, Thorpe-Beeston JG, Snijders RJ, Nicolaides K, et al. (1997) Presence of the 'lemon' sign in fetuses with spina bifida at the 1014-week scan. Ultrasound Obstet Gynecol 10: 403-407.

15. Gembruch U (1997) Prenatal diagnosis of congenital heart disease. Prenat Diagn 17: 1283-1297.
16. Rosendhal H, Kivinen S (1989) Antenatal detection of congenital malformation by routine ultrasonography. Obstet Gynecol 73: 947-951.

17. Lys F, Dewals P, Borlee Gremee I, Billeet A, Vincotte-Mols M, et al. (1989) Evaluation of routine ultrasound examination for the prenatal diagnosis of malformation. EJOGRB 30: 101-109.

18. Todros T, Viora E, Scali R (1992) Diagnostica prenatale dei difetti congeniti. Predittività degli esami ecografici di primo livello. Atti LXVII Congresso Nazionale della Società Italiana di Ginecologia e Ostetricia.

19. Nicolaides KH, Azar G, Byrne D, Mansur C, Marks K, et al. (1992) Fetal nuchal translucency: ultrasound screening for chromosomal defects in first trimester of pregnancy. Br Med 304: 867-889.

20. Souka AP, Snijders RJM, Novakov A, Soares W, Nicolaides KH, et al. (1998) Defects and syndromes in chromosomally normal fetuses with increased nuchal translucency thickness at 10-14 weeks of gestation. Ultrasound Obstet Gynecol 11: 391-400.

21. Spencer K, Souter V, Tul N, Snijders RJM, Nicolaides KH, et al. (1999) A screening program for trisomy 21 at 10-14 weeks using fetal nuchal translucency, maternal serum free beta-human chorionic gonadotropin and pregnancy-associated plasma protein-A. Ultrasound Obstet Gynecol 13: $231-237$.

22. Benacerraf $B$, Barss $V$, Laboda $L$ (1985) A sonographic sign for the detection in the second trimester of the fetus with Down's syndrome. Am J Obstet Gynecol 151: 1078-1079.

23. Snijders RJM, Nicolaides KH (1996) Ultrasound markers for fetal chromosome defects. Canforth, UK: Parthenon Publishing. Assessment of risks.

24. Benacerraf BR (2000) Should sonographic screening for fetal Down syndrome be applied to low risk women? Ultrasound Obstet Gynecol 15: 451-455.

25. Drugan A, Johnson MP, Evans MI (2000) Ultrasound screening for fetal chromosome anomalies. Am J Med Genet 90: 98-107.

26. Bahado-Singh RO, Oz AU, Kovanci E, Deren O, Copel J, et al. (1998) New Down syndrome screening algorithm: ultrasonographic biometry and multiple serum markers combined with maternal age. Am J Obstet Gynecol 179: 1627-1631.

27. Viora E, Grassi Pirrone P, Bastonero S, Errante G, Sciarrone A, et al. Minor sonographic markers of fetal chromosomal anomalies: a review. It J Gynaecol Obstet 11: 79-86.

28. Boyd PA, Chamberlain P, Hicks NR (1998) 6-year experience of prenatal diagnosis in an unselected population in Oxford, UK. Lancet 352: 15771781.

29. Filly RA (2000) Obtetrical sonography: the best way to terrify a pregnant woman. J Ultrasound Med 19: 1-5.

30. Todros T, Faggiano F, Chiappa E, Gaglioti P, Mitola B, et al. (1997) Accuracy of routine ultrasonography in screening heart disease prenatally. Prenat Diagn 17: 901-906.

31. Fesslova V, Nava S, Villa L (1999) Evolution and long term outcome in cases with fetal diagnosis of congenital heart disease: Italian multicentre study. Heart 82: 594-549.

32. Allan LD, Sharland GK, Milburn A, Lockhart SM, Groves AMM, et al. (1994) Prospective diagnosis of 1,006 consecutive cases of congenital heart disease in the fetus. J Am Coll Cardiol 23: 1452-1458.

33. Touati GD, Fermont L, Neveux JY, Vouhe PR, Gay F, et al. (1988) Effects of a systematic fetal detection on the outcome of severe congenital heart disease. Circulation 78: 396.

34. Raymond FL, Simpson JM, Sharland GK, Mackie Ogilvie CM (1997) Fetal echocardiography as a predictor of chromosomal abnormality. Lancet 350 : 930.

35. Paladini D, Calabro R, Palmieri S, D'Andrea T (1993) Prenatal diagnosis of congenital heart disease and fetal karyotyping. Obstet Gynecol 81: 679-682.

36. Yates R (1999) Fetal cardiac abnormalities and their association with aneuploidy. Prenat Diagn 19: 563-566.

37. Paladini D, Rustico M, Todros T, Palmieri S, Gaglioti $P$, et al. (1996) Conotruncal anomalies in prenatal life. Ultrasound Obstet Gynecol 8: 241246.

38. Klein SK, Cans C, Robert E, Jouk PS (1999) Efficacy of routine ultrasound screening for congenital heart disease in Isere County, France. Prenat Diagn 19: 318-322. 
Citation: Bashir AA (2019) Congenital Malformations: Prenatal Diagnosis and Management. Int J Pediatr Neonat Care 5: 149. doi: https://doi.org/10.15344/24552364/2019/149

39. Buskens E, Grobbee DE, Frohn-Mulder IM, Stewart PA, Juttmann RE, et al. (1996) Efficacy of routine fetal ultrasound screening for congenital heart disease in normal pregnancy. Circulation 94: 67-72.

40. Stoll C, Alembik Y, Dott B, Meyer MJ, Pennerath A, et al. (1998) Evaluation of prenatal diagnosis of congenital heart disease. Prenat Diagn 18: 801-807.

41. Hafner E, Scholler J, Schuchter K, Sterniste W, Philipp K, et al. (1998) Detection of congenital heart disease in a low-risk population. Prenat Diagn 18: 808-815.

42. Todros T (2000) Prenatal diagnosis and management of fetal cardiovascular malformations. Curr Opin Obstet Gynecol 12: 87-92.

43. Gagliardi L, Todros T, Candiani GB, Danesino V, Gastaldi AO, et al. (1996) Le cardiopatie fetali. Principi di diagnosi e terapia. Masson, Milano.

44. Marden PM, Smith DW, McDonald MJ (1964) Congenital anomalies in the newborn infant, including minor variations. J Pediatr 64: 357-371.

45. Kalter H, Warkany J (1983) Congenital malformations (first of two parts). N Engl J Med 308: 424-431.

46. Kalter H, Warkany J (1983) Congenital malformations (second of two parts). N Engl J Med 308: 491-497.

47. Bonnet D, Coltri A, Butera G, Fermont L, Le Bidois J, et al. (1999) Detection of transposition of the great arteries in fetuses reduces neonatal morbidity and mortality. Circulation 99: 916-918.

48. Kumar RK, Newburger JW, Gauvreau K, Kamenir SA, Hornberger LK, et al. (1999) Comparison of outcome when hypoplastic left heart and transposition of the great arteries are diagnosed prenatally versus when diagnosis of these two conditions is made only postnatally. Am J Cardiol 83: $1649-1653$.

49. Daubeney PEF, Sharland GK, Cook AC, Keeton BR, Anderson RH, et al (1998) Pulmonary atresia with intact ventricular septum. Impact of fetal echocardiography on incidence at birth and postnatal outcome. Circulation 98: 562-566.

50. Kern JH, Hayes CJ, Michler RE, Gersony WM, Quaegebeur JM, et al. (1997) Survival and risk factor analysis for the Norwood procedure for hypoplastic left heart syndrome. Am J Cardiol 80: 170-174.

51. Neilson JP (2000) Ultrasound for fetal assessment in early pregnancy. The Cochrane Database of Systematic Reviews.

52. Zimmer EZ, Avraham Z, Sujoy P, Goldstein I, Bronshtein M, et al. (1997) The influence of prenatal ultrasound on the prevalence of congenital anomalies at birth. Prenat Diagn 17: 623-628.

53. Bull C (1999) Current and potential impact of fetal diagnosis on prevalence and spectrum of serious congenital heart disease at term in the UK. Lancet 354: $1242-1247$.

54. Todros T, Presbitero P, Gaglioti P, Demarie D (1988) Pulmonary stenosis with intact ventricular septum: documentation of development of the lesion echocardiographically during fetal life. Int J Cardiol 19: 335-360.

55. AIUM Technical Bullettin (1998) Performance of the basic fetal cardiac ultrasound examination. J Ultrasound Med 17: 601-617.

56. Farina A, Malone FD, Bianchi DW (2000) Fetal sonographic findings: analysis of the most frequent patterns and their specificity of association. Am J Med Genet 91: 331-339.

57. Levine D, Barnes PD, Edelman RR (1999) Obstetric MR imaging. Radiology 211: 609-617.

This article was originally published in a special issue:

Perinatal Management of Congenital Anomalies

Handled by Editor(s):

Prof. Wei Cheng

Department of Pediatric Surgery

Beijing United Family Hospital

China 